\title{
The Size and Distribution of Midbrain Dopaminergic Populations are Permanently Altered by Perinatal Glucocorticoid Exposure in a Sex- Region- and Time-Specific Manner
}

\author{
Simon McArthur', Emily McHale' and Glenda E Gillies*,' \\ 'Department of Cellular and Molecular Neuroscience, Division of Neuroscience and Mental Health, Imperial College, London, UK
}

\begin{abstract}
Central dopaminergic (DA) systems appear to be particularly vulnerable to disruption by exposure to stressors in early life, but the underlying mechanisms are poorly understood. As endogenous glucocorticoids (GCs) are implicated in other aspects of neurobiological programming, this study aimed to characterize the effects of perinatal GC exposure on the cytoarchitecture of DA populations in the substantia nigra pars compacta (SNc) and the ventral tegmental area (VTA). Dexamethasone was administered non-invasively to rat pups via the mothers' drinking water during embryonic days 16-19 or postnatal days 1-7, with a total oral intake circa 0.075 or 0.15 mg/ $\mathrm{kg} /$ day, respectively; controls received normal drinking water. Analysis of tyrosine hydroxylase-immunoreactive cell counts and regional volumes in adult offspring identified notable sex differences in the shape and volume of the SNc and VTA, as well as the topographical organization and size of the DA populations. Perinatal GC treatments increased the DA population size and altered the shape of the SNc and VTA as well as the organization of the DA neurons by expanding and/or shifting them in a caudal direction. This response was sexually dimorphic and included a feminization or demasculinization of the three-dimensional cytoarchitecture in males, and subtle differences that were dependent on the window of exposure. These findings demonstrate that inappropriate perinatal exposure to GCs have enduring effects on the organization of midbrain DA systems that are critically important for normal brain function throughout life. Neuropsychopharmacology (2007) 32, |462-1476; doi:I0. I038/s..npp. I 30 I277; published online I 3 December 2006
\end{abstract}

Keywords: dopaminergic neurons; midbrain; perinatal glucocorticoid treatment; sex dimorphism; population size; regional volume

\section{INTRODUCTION}

Midbrain dopaminergic (DA) systems regulate diverse behavioural and cognitive functions that are critical for integrating mammalian responses and adaptations to the environment (Moore and Bloom, 1978). Those originating in the ventral tegmental area (VTA) constitute two major DA pathways: the mesolimbic system projects to the ventral striatum, especially the nucleus accumbens, and is involved in regulating processes controlling emotion, reward, and feeding, whereas the mesocortical system projects to the medial prefrontal cortex which plays a role in cognition and working memory. A second major midbrain DA system forms the mesostriatal or nigrostriatal pathway, which

*Correspondence: Dr GE Gillies, Department of Cellular and Molecular Neuroscience, Division of Neuroscience and Mental Health, Imperial College London, Hammersmith Campus, Du Cane Road, London WI2 ONN, UK, Tel: + 440208383 8037, Fax: + 440208383 8032, E-mail: g.gillies@imperial.ac.uk

Received 29 August 2006; revised II October 2006; accepted 17 October 2006 arises in the substantia nigra pars compacta (SNc), projects to the dorsal striatum, and is central to sensorimotor integration. Malfunction of these pathways is associated with a range of psychiatric disorders, including schizophrenia (Lewis and Levitt, 2002), attention deficit hyperactivity disorder (ADHD), (Solanto, 2002) and substance abuse (Melichar et al, 2001), as well as Parkinson's disease (Braak et al, 2004). Although the etiologies of these conditions remain poorly understood, retrospective studies in humans reveal that vulnerability to develop conditions such as schizophrenia and ADHD has a strong neurodevelopmental component (Cotter and Pariante, 2002; Lewis and Levitt, 2002). Moreover, animal studies provide evidence that exposure to a variety of adverse events in early life can alter adult behaviors as well as neurochemical indicators of midbrain DA activity, such as locomotor activity, DA release, and DA transporter levels (Henry et al, 1995; Brake et al, 2000a; Meaney et al, 2002). These studies clearly suggest that developing central DA systems are particularly sensitive to disruption by brief exposure to early stressors. However, the underlying mechanisms are poorly understood. 
The concept of the early origins of adult disease is now well-established (Barker, 1995). Among other factors, endogenous glucocorticoid (GC) hormones released in response to stressors, either by the fetal or maternal hypothalamopituitary-adrenal (HPA) axis, are thought to play an important role in neurobiological programming in humans and many experimental species (Weinstock, 2001; Welberg and Seckl, 2001; Owen et al, 2005; Van den Bergh et al, 2005). For example, in the rat, prenatal GC treatment and exposure to stress similarly alter adult expression of the GC receptors (GRs) in brain regions that are important in regulating negative feedback within the HPA axis, resulting in permanent changes in circulating corticosterone levels (Barbazanges et al, 1996; Weinstock, 2001; Welberg and Seckl, 2001; Owen et al, 2005). It is also increasingly evident that early exposure to GCs, as well as stressors, has marked effects on animal and human affective and neuromotor behaviors and cognition (Yeh et al, 2004; Owen et al, 2005; Van den Bergh et al, 2005). However, there is little direct evidence to relate the consequences of perinatal GC exposure to enduring changes in specific, phenotypically identified, central neurotransmitter populations.

In order to address this issue we have recently focused on a specific region of the $\mathrm{SNc}$, termed level $\mathrm{B}$ according to Carman et al (1991) ( -5.1 to $-5.4 \mathrm{~mm}$ relative to bregma) that has previously been considered representative of the region as a whole (Dexter et al, 1994), as well as the equivalent region of the VTA, to examine the effects of perinatal exposure to the synthetic GC, dexamethasone, on the adult midbrain DA populations (McArthur et al, 2005). This study demonstrated that the numbers of tyrosine hydroxylase immunoreactive (TH-IR) cells are increased in this portion of each nucleus in the adult offspring of dams given drinking water containing dexamethasone towards the end of gestation (gestational days (GD) 16-19) or during the first week of lactation (post natal days (P) 1-7). During development GCs are known to have profound effects on neurogenesis, neuronal migration, and cell survival in the CNS (Gould and Cameron, 1996; Abraham et al, 2001) and our GC treatment regimens span critical times in the development of midbrain DA neurons (Tepper et al, 1994; Oo and Burke, 1997; Hynes and Rosenthal, 1999). Therefore, the present study aimed to determine to what extent the enduring effects of perinatal GC exposure at level $\mathrm{B}$ of the midbrain DA nuclei are representative of the nucleus as a whole, or whether a localized increase in DA neuronal density could be due to abnormal positioning of the cells. Hence, we have extended our investigations throughout the rostro-caudal extent of the adult SNc and VTA in order to assess effects on the volume and shape of these regions as well as the size and distribution of the DA populations and the size of the individual perikarya after brief exposure prenatally or neonatally to dexamethasone. The need to study both periods of exposure is governed by the knowledge that different outcomes have been reported for pre- and neonatal GC programming of the neuroendocrine axes governing the stress response and prolactin secretion (Welberg et al, 2001; Owen et al, 2005; Theogaraj et al, 2005; McArthur et al, 2006a) as well as behaviors and indicies of neurotransmitter signaling in the cerebral cortex and hippocampus (Welberg et al, 2001; Kreider et al, 2005; Owen et al, 2005; Kreider et al, 2006; Slotkin et al, 2006).
Moreover, many of these changes are sex-specific, and we have shown that GC programming effects on the DA population size in the hypothalamic arcuate nucleus are restricted to females (McArthur et al, 2006a). Therefore, the present investigations have been carried out in both males and females in order to investigate whether males and females are differentially affected by GC programming effects within the midbrain DA populations.

\section{MATERIALS AND METHODS}

\section{Animals}

All animal procedures were carried out under license in accordance with the United Kingdom Animals (Scientific Procedures) Act of 1986. Sprague-Dawley rats were purchased for timed-matings (Harlan Olac, Blackthorn, Beicester, Oxfordshire, UK) and housed in the Comparative Biology Unit at Charing Cross Hospital (Faculty of Medicine, Imperial College, London) under controlled lighting (on $0800-2000 \mathrm{~h}$ ), temperature $\left(21-23^{\circ} \mathrm{C}\right.$ ) and humidity $(63 \%)$, with standard rat chow and drinking water (except as described below) provided ad libitum. On arrival, males and females were caged separately, and allowed to acclimatize to their new environment for 1 week, after which groups of one male and two female rats were housed together overnight and the presence of vaginal plugs the following morning was taken to confirm mating; pregnancy was confirmed approximately 6 days later by palpation. The timed pregnant rats were housed five per cage until GD 15, when they were caged singly in preparation for giving birth. From GD 19/20 pregnant rats were monitored several times a day and the day of birth was defined as day 0 . Offspring were weaned at 3 weeks, after which male and female animals were housed separately in standard, wire-topped cages in groups of five per cage and were allowed to grow to young adulthood with no further treatment. At $68 \pm 2$ days of age animals were killed by decapitation between 0900 and $1000 \mathrm{~h}$ to minimize effects associated with circadian rhythms.

\section{Dexamethasone Treatment Regimens}

In order to avoid potential confounding effects of injection stress and also handling of the newborn pups, which may itself produce long-lasting effects on behaviour and mesencephalic DA systems in particular (Meaney et al, 2002), dexamethasone was administered non-invasively using the method established by McArthur et al (2005) and Theogaraj et al (2005) where dexamethasone sodium phosphate (Faulding Pharmaceuticals Plc., Royal Leamington Spa, UK) is added to the drinking water of pregnant or nursing dams between embryonic days 16-19 (E16-E19, $0.5 \mu \mathrm{g} / \mathrm{ml}$ ) or postnatal days $1-7$ (P1-P7, $1 \mu \mathrm{g} / \mathrm{ml})$. Using this oral route, dexamethasone is able to reach the developing fetuses or neonates via the placenta (Funkhouser et al, 1978) or milk (Tainturier et al, 1982), respectively. Although the means were not available to us to calculate directly the levels of drug in the fetal and neonatal plasma, we have previously used available pharmacokinetic data that allow us to estimate, from the amount of dexamethasone ingested by the dams, that similar concentrations are achieved in the 
fetus and neonate (circa $30 \mathrm{ng} / \mathrm{ml}$ (McArthur et al, 2005)). Allowing for the greater GC potency of dexamethasone, which is reported to be between one and two orders of magnitude greater than that of corticosterone, it would appear that the levels attained can be considered comparable to the GC potency that prevails following stressinduced activation of the maternal HPA axis. On the basis that the mothers' daily intake of water was approximately $50 \mathrm{ml}$ (McArthur et al, 2005), we calculate also that the dexamethasone dosage (approximately 75 and $150 \mu \mathrm{g} / \mathrm{kg} /$ day for prenatal and neonatal treatments, respectively) is within the range of that used clinically to mature the fetal lung in cases of threatened premature birth. As previously reported (McArthur et al, 2005; Theogaraj et al, 2005; McArthur et al, 2006a), these dexamethasone treatments had no significant effects on the outcome of the pregnancies, no discernable influence on maternal behavior and no effect on adult body weight. However, in order to minimize any potential effects of litter of origin and individual differences in maternal care, animals for each of the dexamethasone treatment groups and the control group (normal drinking water) ( $n=8$ per group) were drawn from three different litters for the analyses described below.

\section{Tyrosine Hydroxylase Immunohistochemistry}

After decapitation, brains were rapidly removed and cut coronally at the level of the infundibular stem (bregma $-4.16 \mathrm{~mm}$ ). Hindbrain halves were immersed in $4 \%$ formaldehyde in phosphate-buffered saline (PBS), (0.1 $\mathrm{M} \mathrm{NaH}_{2-}$ $\mathrm{PO}_{4} \cdot 2 \mathrm{H}_{2} \mathrm{O}, 0.1 \mathrm{M} \mathrm{Na} 2 \mathrm{HPO}_{4} \cdot 12 \mathrm{H}_{2} \mathrm{O}, 0.15 \mathrm{M} \mathrm{NaCl}$ (all VWR International, $\mathrm{UK}), \mathrm{pH}$ 7.4) for one week, cryoprotected by immersion in $20 \%$ sucrose in PBS for $48 \mathrm{~h}$, then frozen and stored at $-80^{\circ} \mathrm{C}$. Two series of alternate $20 \mu \mathrm{m}$ sections were cut using a cryostat (Bright Instruments Ltd, Huntingdon, $\mathrm{UK}$ ) maintained at $-22^{\circ} \mathrm{C}$, and were stored in an antifreeze solution (0.1 M NaH $2 \mathrm{PO}_{4} . \mathrm{H}_{2} \mathrm{O}, 0.05 \mathrm{M} \mathrm{Na}_{2} \mathrm{HPO}_{4}, 0.15 \mathrm{mM}$ $\mathrm{NaCl}, 50 \% \mathrm{v} / \mathrm{v}$ ethanediol (all VWR International), 1\% w/v polyvinylpyrrolidone, $0.1 \% \mathrm{w} / \mathrm{v} \mathrm{NaN}_{3}$ (both Sigma-Aldrich, UK)) at $-20^{\circ} \mathrm{C}$ until required.

Immunostaining was carried out on free-floating sections essentially as described previously (Datla et al, 2003). Briefly, PBS was used to rinse sections before they were incubated for $1 \mathrm{~h}$ in $20 \%$ normal goat serum (NGS) (Serotec, Oxford, UK) to saturate nonspecific binding sites. Sections were permeabilised with $0.05 \%$ Triton X-100 (VWR International, UK) in $1 \%$ NGS in PBS for 5 min before being incubated overnight under constant agitation with rabbit anti-rat tyrosine hydroxylase primary antibody (Chemicon, Chandlers Ford, UK), diluted 1:2000 in 1\% NGS in PBS. Using the female SNc, one set of adjacent sections was also incubated with a monoclonal mouse anti-mouse NeuN (Chemicon Ltd., UK) diluted 1:500 in order to estimate effects of treatments on total neuronal numbers. Following three rinses in $1 \%$ NGS in PBS immunolabeled cells were visualized using an ABC Vectorstain kit (Vector Laboratories, Peterborough, UK), using $0.025 \%$ diaminobenzidine tetrahydrochloride and $0.01 \%$ hydrogen peroxide as chromogens (VWR International, UK). Sections were mounted on gelatin-coated microscope slides and were allowed to air-dry before being coverslipped. As it was not feasible to stain all tissue sections concurrently, staining was done in
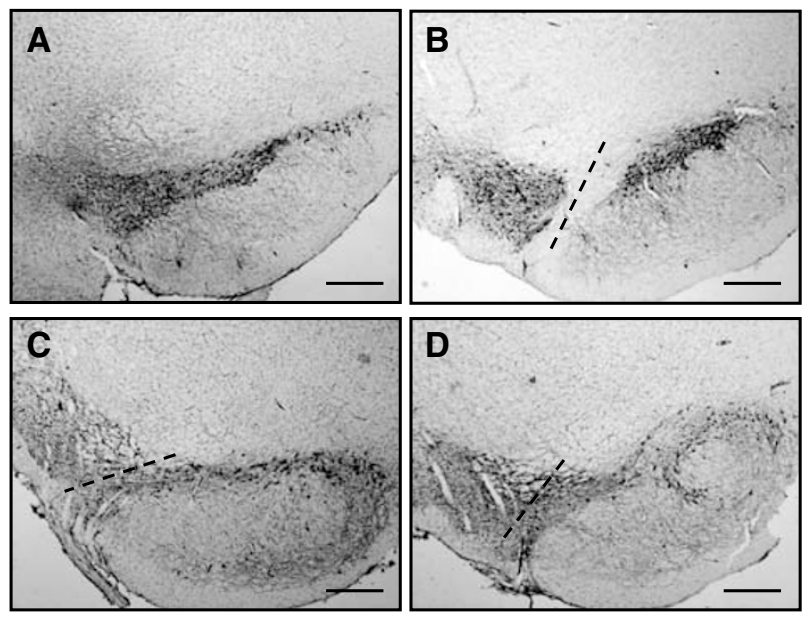

Figure I Identification of the different levels of the SNc and VTA using $\mathrm{TH}$ immunohistochemistry, and the parcellation scheme described by Carman et al (|99|). Brain Res 553: 275-283. Approximate distances from bregma are: level $A-4.8 \mathrm{~mm}$, level $B-5.1 \mathrm{~mm}$, level $C-5.4 \mathrm{~mm}$ and level $\mathrm{D}-5.7 \mathrm{~mm}$. For levels $\mathrm{B}, \mathrm{C}$, and $\mathrm{D}$ the $\mathrm{SNc}$ is to the right of the dashed line, whereas the VTA is to its left. The scale bar represents $230 \mu \mathrm{m}$.

batches using tissues from approximately 10 animals, which were randomly selected from all six treatment groups (male and female groups, each receiving pre- or post natal GC exposure, plus controls with normal drinking water).

The TH-IR cells within the SNc and VTA were counted using an image analysis software package (Image ProPlus 4.5, Media Cybernetics, Finchampstead, UK). Boundaries of the SNc and VTA were defined by examining the size and shape of the TH-IR neuronal groups and juxtaposition of other landmarks, and through reference to a standard rat atlas (Paxinos and Watson, 1986; Murray et al, 2003), with the rostro-caudal extent of the SNc being between $-4.8 \mathrm{~mm}$ and $-6.0 \mathrm{~mm}$ with respect to bregma, and that of the VTA being between $-5.1 \mathrm{~mm}$ and $-6.0 \mathrm{~mm}$ with respect to bregma. The SNc can be clearly distinguished from surrounding non-DA regions of the thalamus dorsally and the substantia nigra pars reticulata ventrally by the presence of TH-IR cells, and from the adjacent VTA by the third cranial nerve tract that runs between the two nuclei. The VTA was delineated by the TH immunopositive region bordered medially by the interfascicular nucleus and the interpeduncular nucleus, and dorsally by the parabrachialpigmented nucleus. In order to detect any regional differences throughout the nuclei, sections containing the SNc/ VTA were divided into four levels, each spanning $300 \mu \mathrm{m}$, according to the method of Carman et al (1991). Thus a set of sections beginning at $-4.8 \mathrm{~mm},-5.1 \mathrm{~mm},-5.4 \mathrm{~mm}$, and $-5.7 \mathrm{~mm}$ with respect to bregma were identified and are referred to as levels A, B, C, and D, respectively (Murray et al, 2003), as shown in Figure 1.

\section{Neuronal Cell Counts, Cell Size, and Regional Volumes}

As described in detail elsewhere (Murray et al, 2003; McArthur et al, 2005; McArthur et al, 2006a), a digital image (magnification $\times 100$ ) of each section was captured using an image analysis system consisting of a CoolSNAP-Pro camera (Roper Scientific, Marlow, UK) attached to a Nikon 
Eclipse E800 microscope (Media Cybernetics, UK). To ensure objectivity, images were coded and stored in a manner that rendered the person performing the cell analysis unaware of the treatment groups. Images were projected onto a PC monitor and the sections were analyzed by manually counting all of the TH-IR cells located within the two nuclei. In each animal the total number of TH-IR cells in alternate sections at each of the four levels was counted; staining and counting every second section eliminates the possibility of double-counting cells. At each level counts were then summated and doubled (to account for total number of sections) to give an estimate of the total TH-IR population per level for each animal within a group and the individual values were used to calculate the group means ( $n=8$ animals per group). This profile-based counting technique for serial reconstruction has proven the most appropriate method when cell numbers are relatively low (Hart and Terenghi, 2004), and the twodimensional method, which we have employed previously (Murray et al, 2003; McArthur et al, 2005, 2006a), enables counting of all cells across the whole of the coronal plane of the SNc and VTA, where TH immunohistochemistry completely delineates nuclear margins. This provides a large sampling window, enabling highly accurate assessment in the $(x, y)$ plane, which compares favorably with three-dimensional (3D) counting methods (Benes and Lange, 2001).

In order to estimate TH-IR cell size, six TH-IR cells per level per animal were randomly chosen from digital images of coded sections and the cross-sectional area calculated. The mean cell area per level per animal were pooled to form the group means $(n=8)$.

The volumes of the SNc and VTA regions used for TH-IR cell counting were estimated using the method of Cavalieri (Brodski et al, 2003; McArthur et al, 2005; Morris et al, 2005). Briefly, following projection of an image of the section at $\times 40$ magnification on a PC monitor as described above, the cross-sectional area for each nucleus, delineated by the presence of TH-IR cells, in every second section was measured and their sum (for each level or whole nucleus) was multiplied by $20 \mu \mathrm{m}$ (section thickness before staining) and doubled (to account for alternate sections), with allowance made for further tissue shrinkage owing to staining, mounting, etc. which we estimated as $3.3 \pm 1.7 \%$ by measurement with an electronic microcator (Bonthius et al, 2004).

\section{Statistical Analysis}

All statistical analyses were carried out using Sigmastat 3.0 software (Jandel Corporation, CA, USA). Preliminary analysis was undertaken to show that data were normally distributed (Kolmogorov-Smirnov test) and that variances were equal (Levene's Median test). To avoid the type I statistical errors that can result from repeated testing of the data sets, global ANOVAs were initially performed on data groupings for each parameter measured, that is, neuron number, nucleus volume, neuron size, and neuron distribution within the nucleus, with gender, level of the SNc or VTA and dexamethasone treatment regimen as factors. Data were then subdivided according to the interacting factors, and lower order effects of gender and dexamethasone treatment were examined by ANOVA, with post hoc analysis by Bonferroni's corrected Student's $t$-test. A probability value of $p<0.05$ was accepted as significant in all cases.

\section{RESULTS}

Table 1 presents the results of a global three-way ANOVA analysis for TH-IR cell number, regional volume and distribution of TH-IR cells in the SNc and VTA and illustrates a significant three-way interaction between sex, level, and treatment.

\section{TH-IR Cell Numbers in the Adult SNc}

In the control groups, total cell counts throughout the SNc confirmed previous observations (Murray et al, 2003; Dewing et al, 2006) that adult male rats possess significantly more TH-IR neurons than females, by approximately $15 \%$, and the present data reveal that this was due to increased numbers in the male at levels A (open histograms, Figure 2a $v s$ 2b). Prenatal GC treatment significantly increased the total number of TH-IR cells in the SNc in both sexes $(p<0.05)$, and analysis at each level showed that this was due primarily to a significant effect at level $B$ and $D$ in males, whereas in females this effect was seen at all levels (Figure 2a and b, hatched histograms). Neonatal treatment also increased the overall total TH-IR cell counts in males with significant effects $(p<0.05)$ at levels A and D (Figure 2a, closed histograms), and in females across all four levels (Figure 2b, closed histograms). In order to investigate whether the effects of GCs on neuron number were nonspecific, total neuronal number, as determined by counts of cells positive for NeuN (a nuclear protein expressed in most post-mitotic vertebrate neurons (Mullen et $a l, 1992$ ), were evaluated for the female SNc and revealed no significant effect of prenatal or neonatal treatment (Table 2).

\section{TH-IR Cell Numbers in the Adult VTA}

In the control groups the total TH-IR cell count was significantly less in the VTA in adult males compared with females, principally due to fewer cells at level C (Figure $3 a v s$ $\mathrm{b}$, open histograms, $p<0.05$ ). Both GC treatment regimens similarly increased TH-IR cell numbers at all levels in males and females, resulting in an overall 65 and 50\% increase after prenatal or neonatal exposure, respectively (Figure 3a and $b$, hatched and closed histograms, respectively).

\section{Regional Volumes in the Adult SNc}

In order to gain an understanding of the shape of the midbrain DA nuclei, the regional volumes occupied by the TH-IR cells were analyzed. In the control SNc, the total volume was significantly greater in females compared with males by $46 \%$ owing to significant differences at levels B, C, and $\mathrm{D}$ (Figure $4 \mathrm{a} v s \mathrm{~b}$, open histograms, $p<0.05$ ), resulting in a striking sex difference in the overall shape. Prenatal GC exposure in the male significantly increased adult SNc volumes at levels $\mathrm{C}$ and $\mathrm{D}$, resulting in an overall increase of $23 \%$, whereas in females volume was decreased at levels $\mathrm{A}$ and $\mathrm{C}$ and increased at $\mathrm{D}$, with a net reduction of $11 \%$ in the 


\section{GCs disrupt midbrain DA cytoarchitecture}

S McArthur et al

Table I Results of Global Three-Way ANOVA Analysis for the SNc and VTA, Investigating Differences in Total TH-IR Cell Number, Nucleus Volume, and the Distribution of TH-IR Cells within the Nucleus

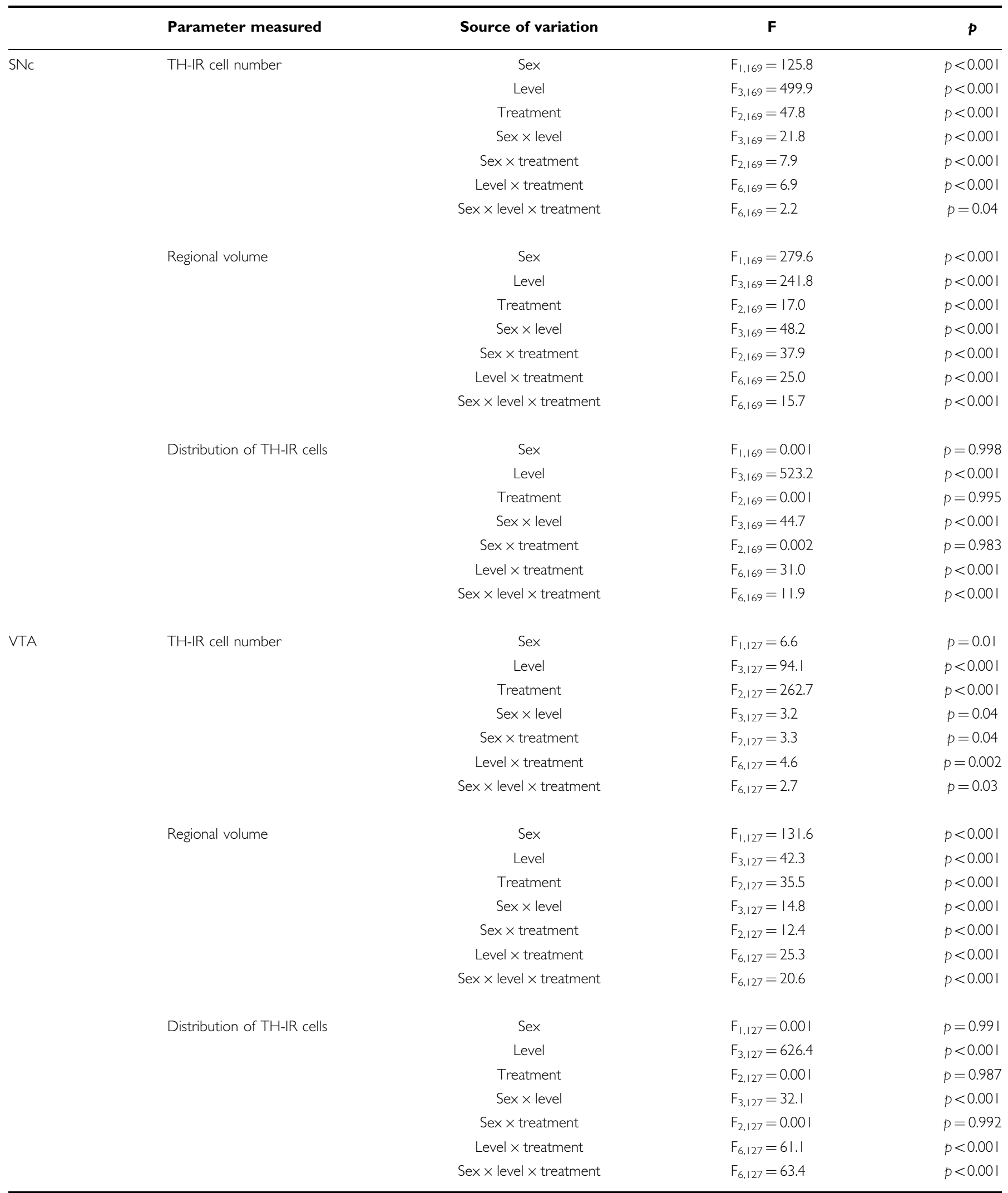

Data from the analysis of individual neuron size are not presented, as none of the factors investigated had any significant effect. Parameters in which a three-way interaction term was significant were then subjected to further analysis as described. 

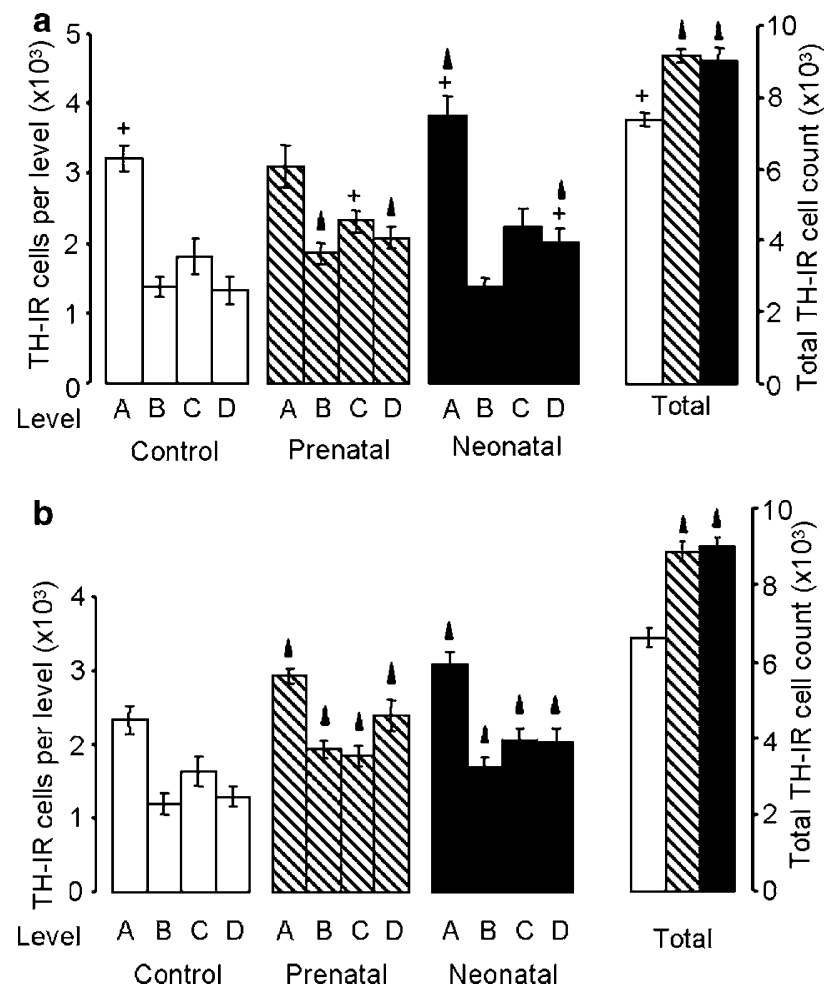

Figure 2 Total TH-IR cell counts at levels A-D (according to Carman et al (1991)) and over the whole SNc of (a) male and (b) female rats in adulthood after treatment with dexamethasone via the maternal drinking water prenatally on embryonic days $16-19(0.5 \mu \mathrm{g} / \mathrm{ml}$, $\mathbf{\nabla})$ or neonatally on days $\mid-7(\mid \mu g / m l, ~ \boldsymbol{~})$ compared to the control offspring of dams receiving normal drinking water $(\square)$. Data are means \pm SEM, $n=8$ animals per treatment group. $\boldsymbol{\Delta}$ Indicates significant effect of treatment, $p<0.05$ increased for dexamethasone treated vs control animals; + indicates significant sex difference $p<0.05$ vs females in the same treatment group.

Table 2 Total Neuron Counts in the Female SNc

NeuN-positive cell number (average per $20 \mu \mathrm{m}$ section)

\begin{tabular}{llll}
\cline { 2 - 4 } Level & Control & Prenatal & Neonatal \\
\hline A & $665 \pm 37$ & $640 \pm 23$ & $657 \pm 25$ \\
$B$ & $567 \pm 32$ & $546 \pm 22$ & $557 \pm 30$ \\
C & $574 \pm 29$ & $460 \pm 14$ & $575 \pm 18$ \\
$D$ & $599 \pm 33$ & $484 \pm 25$ & $528 \pm 30$ \\
\hline
\end{tabular}

The total number of neurons (identified by NeuN immunohistochemistry) in the female SNc were not influenced by prenatal or neonatal dexamethasone treatment.

overall volume (Figure $4 \mathrm{a}$ and $\mathrm{b}$, hatched histograms). Compared with prenatal treatment, neonatal GC exposure in males had a more varied effect to reduce $\mathrm{SNc}$ volume at level $\mathrm{A}$, but to increase it at levels $\mathrm{C}$ and $\mathrm{D}$, with no net effect on overall volume (Figure $4 \mathrm{a}$, closed histograms). Neonatal treatment of females significantly reduced SNc volume at levels $\mathrm{A}$ and $\mathrm{C}$, resulting in an overall decrease of approximately $13 \%$ (Figure $4 \mathrm{~b}, p<0.05$ ). Although the overall shape of the SNc had varied in response to both GC
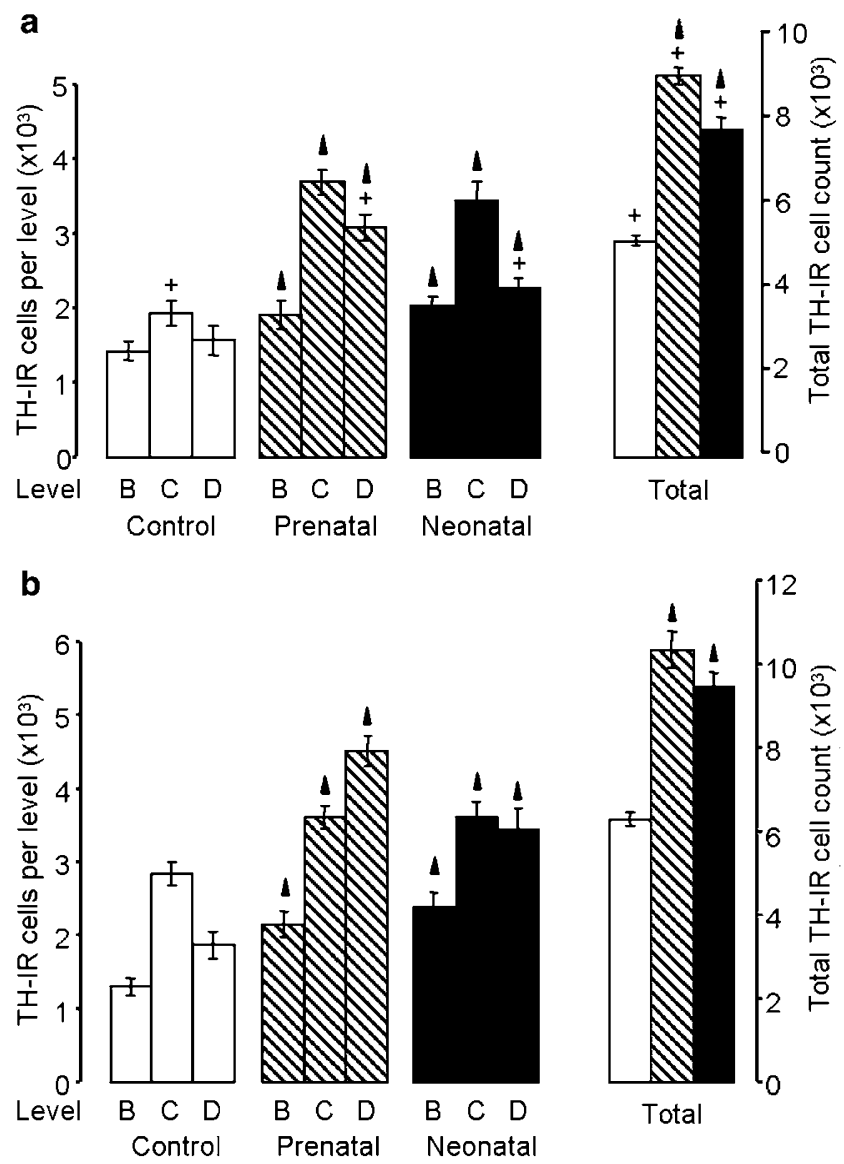

Figure 3 Total TH-IR cell counts at levels B-D (according to Carman et al (|99|)) and over the whole VTA of (a) male and (b) female rats in adulthood after treatment with dexamethasone via the maternal drinking water prenatally on embryonic days $16-19(0.5 \mu \mathrm{g} / \mathrm{ml}, \mathbf{N})$ or neonatally on days $\mid-7(\mid \mu \mathrm{g} / \mathrm{ml}, \boldsymbol{\square})$ compared to the control offspring of dams receiving normal drinking water $(\square)$. Data are means \pm SEM, $n=8$ animals per treatment group. $\boldsymbol{\Delta}$ Indicates significant effect of treatment, $p<0.05$ increased for dexamethasone treated vs control animals; + indicates significant sex difference $p<0.05$ vs females in the same treatment group.

treatment regimens in both sexes, the female-dominant sex difference in total volume was, however, maintained in all treatment groups.

\section{Regional Volumes in the Adult VTA}

In the control VTA the total volume was significantly greater in adult females compared with males by $32 \%$ due to significant differences at levels $\mathrm{C}$ and $\mathrm{D}$ (Figure $5 \mathrm{a} v s \mathrm{~b}$, open histograms; $p<0.05$ ), indicating a clear sex difference in the overall shape. Prenatal GC exposure in the male markedly increased adult volumes at levels $\mathrm{C}$ and $\mathrm{D}$, with an overall increase of $28 \%$ in total volume (Figure $5 \mathrm{a}$ ). In females prenatal treatment reduced volume at level $\mathrm{C}$, but increased it level $\mathrm{D}$, with a net total increase of $12 \%$. In contrast to the prenatal regimen, neonatal GC exposure in males had no overall significant effect on total volume, although a significant increase was seen at level $\mathrm{C}$ (Figure 4a). In females also, neonatal GC treatment did not significantly affect overall volume, although there was a 

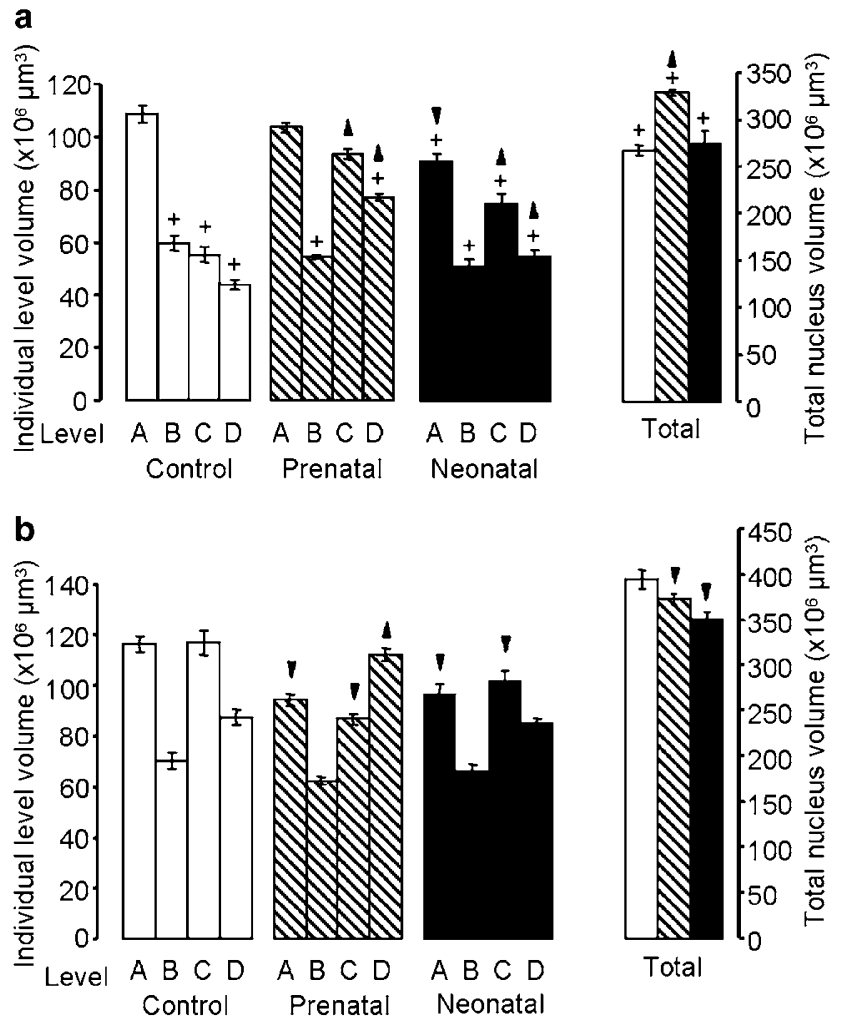

Figure 4 Changes in volume (levels A-D and total) and overall shape of the $\mathrm{SNc}$ in adult (a) male and (b) female rats after treatment with dexamethasone via the maternal drinking water prenatally on embryonic days 16-19 $(0.5 \mu \mathrm{g} / \mathrm{ml}, \mathbf{\nabla})$ or neonatally on days $\mid-7(\mid \mu \mathrm{g} / \mathrm{ml}, \mathbf{\square})$ compared to the control offspring of dams receiving normal drinking water $(\square)$. Data are means \pm SEM, $n=8$ animals per treatment group. $\boldsymbol{\Lambda}, \boldsymbol{\nabla}$ Indicates significant effect of treatment, $p<0.05$ increased or decreased respectively for dexamethasone treated vs control animals; + indicates significant sex difference $p<0.05$ vs females in the same treatment group.

significant increase at level D. Like the SNc, the femaledominant sex difference in total volume was, however, maintained after pre- and neonatal GC treatments, although the overall shape of the VTA had varied in both sexes.

\section{TH-IR Cell Size and Packing Density}

In order to determine whether the size of the DA cells was influenced by perinatal GC exposure, which could contribute to the changes seen in regional volumes, the cross sectional area of TH-IR cells was measured (Table 3 ). No significant effects of gender, treatment or level in the $\mathrm{SNc}$ or VTA were detected. However, in agreement with others (German and Manaye, 1993; Bayer et al, 1995; Lieb et al, 1996) the DA cells in the SNc were significantly larger than those of the VTA $(p<0.01)$.

As the direction of changes in cell counts and regional volumes after perinatal GC treatment did not follow the same pattern, data were also analyzed in terms of cell density (Table 4). In control males TH-IR cells were more densely packed at all levels of the SNc compared with females owing to their greater cell number and smaller regional volume. However, in the VTA there were no sex differences in packing density, as the lower number of TH-IR cells in males is accompanied by a smaller regional
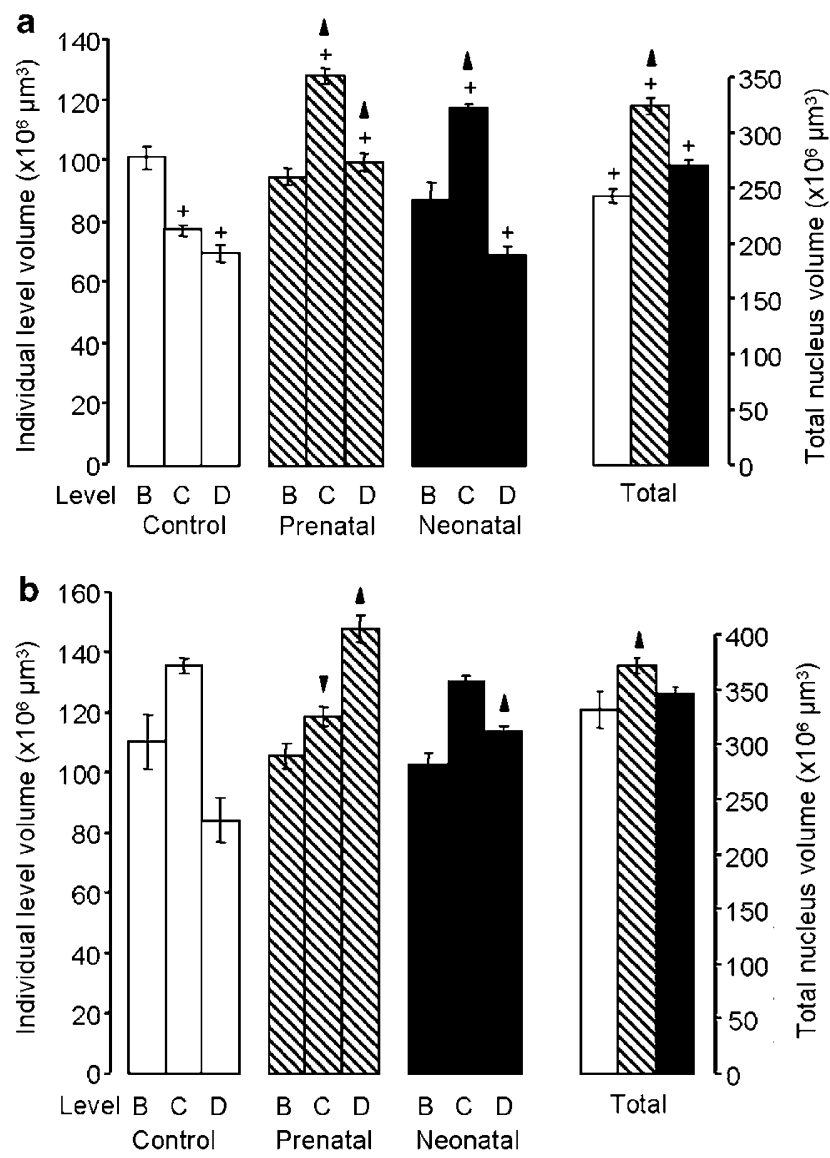

Figure 5 Changes in volume (levels B-D and total) and overall shape of the VTA in adult (a) male and (b) female rats after treatment with dexamethasone via the maternal drinking water prenatally on embryonic days 16-19 $(0.5 \mu \mathrm{g} / \mathrm{ml}, \mathbf{N \nabla})$ or neonatally on days I-7 ( $\mu \mathrm{g} / \mathrm{ml}, \mathbf{\square})$ compared to the control offspring of dams receiving normal drinking water ( $\square)$. Data are means \pm SEM, $n=8$ animals per treatment group. $\boldsymbol{\Lambda}, \boldsymbol{\nabla}$ Indicates significant effect of treatment, $p<0.05$ increased or decreased respectively for dexamethasone treated vs control animals; + indicates significant sex difference $p<0.05$ vs females in the same treatment group.

volume. Significant changes in SNc and VTA packing density were observed at one or more levels for both sexes and treatments, except for the SNc of the male group treated prenatally with GCs, where cell density was not significantly different from controls.

\section{Distribution of TH-IR Cells}

In order to provide a clearer view of the distribution of TH-IR cells throughout the SNc and VTA and how this might be influenced by perinatal GC treatment, Figure 6 presents the proportion of total TH-IR cells that are located at each level. In control males almost half the TH-IR cells of the SNc were present at level A, which was significantly more than the proportion at this level in females (Figure 6a, $p<0.05)$. The remainder of the cells in the control male SNc were equally distributed across levels B, C, and D, whereas in females significantly greater proportions were located at levels $\mathrm{C}$ and D. The distribution of TH-IR cells in the SNc is thus sexually dimorphic. Prenatal GC treatment of males reduced the proportion of TH-IR located at level A, but 
Table 3 Size of TH-IR Cells in Midbrain Nuclei are not Influenced by Perinatal Dexamethasone Treatment

\begin{tabular}{|c|c|c|c|c|c|}
\hline & & \multicolumn{4}{|c|}{ Cell cross-sectional area $\left(\mu \mathrm{m}^{2}\right)$} \\
\hline & & Level & Control & Prenatal DEX (E I6-19, $0.5 \mu \mathrm{g} / \mathrm{ml})$ & Neonatal DEX (PI-7, I $\mu \mathrm{g} / \mathrm{ml})$ \\
\hline & & $\mathrm{B}$ & $234.1 \pm 15.5$ & $263.9 \pm 8.5$ & $234.9 \pm 6.2$ \\
\hline & & C & $251.4 \pm 9.4$ & $264.5 \pm 8.0$ & $236.2 \pm 16.3$ \\
\hline & & B & $249.5 \pm 9.7$ & $242.5 \pm 10.9$ & $238.8 \pm 10.5$ \\
\hline & & C & $253.2 \pm 14.4$ & $258.6 \pm 9.4$ & $221.7 \pm 16.6$ \\
\hline & & $\mathrm{D}$ & $226.4 \pm 14.2$ & $262.0 \pm 20.1$ & $220.3 \pm 13.9$ \\
\hline \multirow[t]{3}{*}{ VTA } & Male & $\mathrm{B}$ & $147.9 \pm 1 \mid .1$ & $162.4 \pm 11.8$ & $165.7 \pm \mid 1.1$ \\
\hline & & C & $144.8 \pm 7.6$ & $135.6 \pm 6.5$ & $137.2 \pm 4.0$ \\
\hline & & $\mathrm{D}$ & $171.3 \pm 11.1$ & $147.5 \pm 6.3$ & $145.4 \pm 18.1$ \\
\hline
\end{tabular}

Cross-sectional areas of six cells per level, randomly chosen from sections at each level, were calculated, and mean values for each animal were pooled to give group means \pm SEM ( $n=8$ animals per group) for adult male and female rats after treatment with dexamethasone via the maternal drinking water on embryonic days $16-19$ (prenatal $0.5 \mu \mathrm{g} / \mathrm{ml}$ ) or neonatally on days $\mid-7(\mid \mu \mathrm{g} / \mathrm{ml})$ compared to the offspring of dams receiving normal drinking water.

Table 4 Effect of Perinatal Dexamethasone Treatment on TH-IR Cell Density in the Adult SNc and VTA

\begin{tabular}{|c|c|c|c|c|c|}
\hline & & \multicolumn{4}{|c|}{ TH-IR cell density $\left(\times 10^{4}\right.$ cells $\left./ \mathrm{mm}^{3}\right)$} \\
\hline & & Level & Control & Prenatal DEX (EI6-19) & Neonatal DEX (PI-7) \\
\hline & & B & $2.5 \pm 0.2+$ & $3.0 \pm 0.1$ & $2.9 \pm 0.2$ \\
\hline & & C & $3.2 \pm 0.3+$ & $2.6 \pm 0.1$ & $3.1 \pm 0.4+$ \\
\hline & & B & $1.8 \pm 0.1$ & $3.0 \pm 0.1 *$ & $2.7 \pm 0.2 *$ \\
\hline & & C & $1.6 \pm 0.1$ & $2.1 \pm 0.1$ & $2.2 \pm 0.2$ \\
\hline & & $\mathrm{D}$ & $1.8 \pm 0.1$ & $2.3 \pm 0.1$ & $2.6 \pm 0.1 *$ \\
\hline \multirow[t]{3}{*}{ VTA } & Male & B & $1.5 \pm 0.1$ & $2.1 \pm 0.1 *$ & $2.4 \pm 0.1 *$ \\
\hline & & C & $2.5 \pm 0.1$ & $3.0 \pm 0.1 *$ & $3.0 \pm 0.1 *$ \\
\hline & & $\mathrm{D}$ & $2.4 \pm 0.2$ & $3.2 \pm 0.1 *$ & $3.1 \pm 0.2^{*}$ \\
\hline
\end{tabular}

Data are plotted as mean values \pm SEM ( $n=8$ animals per group) for adult male and female rats after treatment with dexamethasone via the maternal drinking water on embryonic days $16-19$ (prenatal, $0.5 \mu \mathrm{g} / \mathrm{ml}$ ) or neonatally on days $1-7(\mid \mu \mathrm{g} / \mathrm{ml}$ ) compared to the offspring of dams receiving normal drinking water.

* $p<0.05$ vs control, $+p<0.05$ vs similarly treated female group.

increased the proportions at $\mathrm{C}$ and $\mathrm{D}$. In females prenatal GCs reduced the proportion of cells at levels $\mathrm{A}$ and $\mathrm{C}$, but increased it at D. Neonatal GC treatment in males increased the proportion of cells only at level $\mathrm{C}$, whereas in females it reduced the proportion at $\mathrm{C}$, but increased it at $\mathrm{D}$.

In the control VTA, like the SNc, the proportion of TH-IR cells was fairly equally distributed across levels B-D in males, whereas in females level $\mathrm{C}$ contained by far the greatest proportion of cells (almost 50\%), again illustrating a clear sex difference in DA cell distribution (Figure $6 \mathrm{~b}$ ). Prenatal GC treatment in males decreased the proportion of TH-IR cells at level B, but increased it at C and D, whereas in females proportions were reduced at $\mathrm{C}$ and increased at D. Similar to prenatal treatment, neonatal treatment in males altered TH-IR cell distribution at levels B (decrease) and C (increase), but had no effect at D. In 


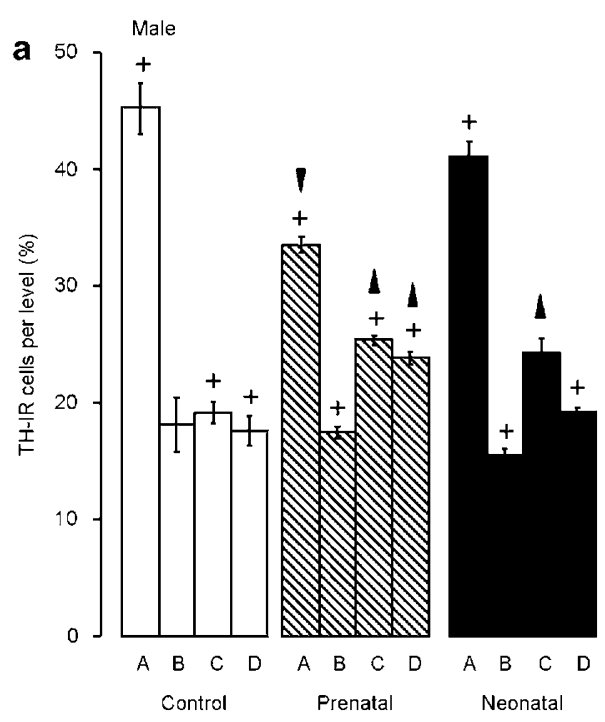

Female
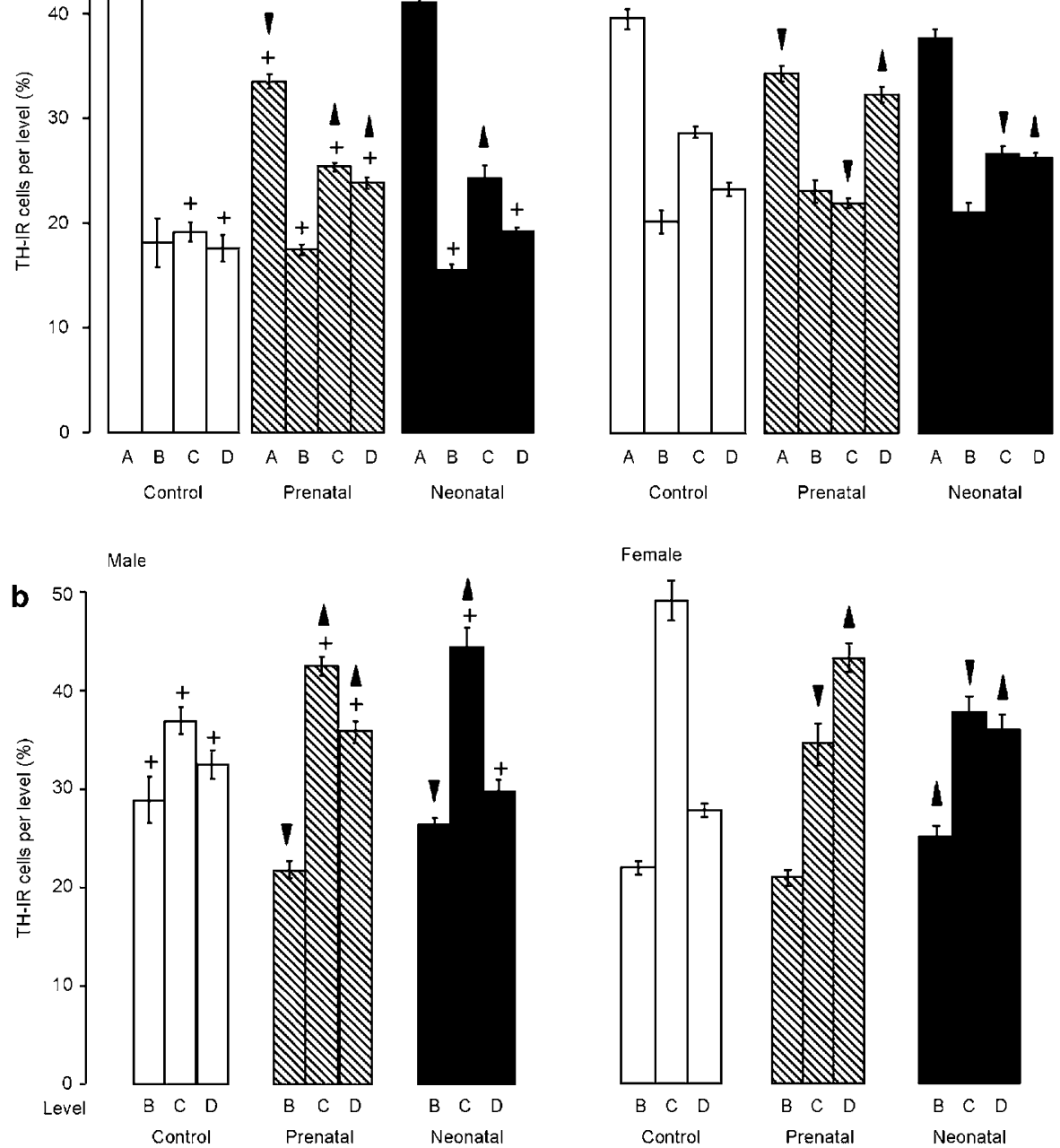

Figure 6 Proportion of TH-IR cells located at each level throughout the (a) SNc and (b) VTA of adult male and female rats after treatment with dexamethasone via the maternal drinking water prenatally on embryonic days $16-19(0.5 \mu \mathrm{g} / \mathrm{ml}$, $\mathbf{\nabla})$ or neonatally on days $\mid-7$ (I $\mu \mathrm{g} / \mathrm{ml}$, $\mathbf{\square})$ compared to the control offspring of dams receiving normal drinking water $(\square)$. Data are means \pm SEM, $n=8$ animals per treatment group. $\boldsymbol{\Delta}, \boldsymbol{\nabla}$ Indicates significant effect of treatment, $p<0.05$ increased or decreased respectively for dexamethasone treated vs control animals; + indicates significant sex difference $p<0.05$ vs females in the same treatment group.

females neonatal treatment increased the proportion at B and $\mathrm{D}$, but decreased it at $\mathrm{C}$.

\section{DISCUSSION}

This study has identified novel striking sex differences in the shape and volume of the adult SNc and VTA as well as the distribution and size of the DA populations in these regions. The results also show for the first time that brief perinatal exposure to the synthetic GC, dexamethasone, produces long-term changes in these parameters, with a notable feminization of the 3D cytoarchitecture in males. These results extend our initial observation that DA cell numbers are increased by perinatal GC treatment at level B in the VTA and SNc (McArthur et al, 2005) and, additionally, they provide the first evidence for permanent structural programming of phenotypically identified neuronal populations by GCs. These findings of enduring altered cytoarchitecture offer a novel mechanism to explain how the early environment may adversely affect normal physiological processes in the brain and the midbrain DA systems in particular. They therefore support the concept that developing midbrain DA populations are highly susceptible to environmental perturbations in early life and illustrate that raised levels of GCs during the perinatal period, as may occur in response to stress, infections or therapeutic use, have the potential to alter neural systems that are critically important for normal brain function throughout life.

\section{Dexamethasone Treatment Regimens}

The sensitivity of developing midbrain DA systems to perturbations in the early environment are evidenced by enduring changes in locomotor or neurochemical responses 
(Henry et al, 1995; Brake et al, 2000b; Meaney et al, 2002). In addition, we have observed marked changes in striatal DA levels in adult rats that received 'control' manipulations (handling and saline injections; Murray, McArthur, and Gillies, unpublished observations). For these reasons we adopted the non-invasive method of administering dexamethasone via the maternal drinking water (McArthur et al, 2005, 2006a; Theogaraj et al, 2005, 2006). From the volume of water ingested, this represents a total daily dose of approximately $0.075 \mathrm{mg} / \mathrm{kg}$ prenatally and $0.15 \mathrm{mg} / \mathrm{kg}$ postnatally. On the basis of available pharmacokinetic data, including consideration of the bioavailability of orally administered dexamethasone (66\%), its distribution ratio between fetal/maternal plasma or between plasma and milk, and its steady-state volume of distribution, we have estimated that the average steady state level of dexamethasone in fetal and neonatal plasma is similar and of the order of $30 \mathrm{ng} / \mathrm{ml}$ (75 nM) (McArthur et al, 2005, and references therein). However, a recent detailed study would suggest that this is likely to be an over-estimation (Samtani et al, 2006a,b). The work by Samtani and co-workers aimed to provide a pharmacokinetic and pharmacodynamic analysis of the optimal treatment regimen for the pregnant rat in order to mimic the endogenous late-gestational rise in the plasma GC concentration that is necessary for fetal lung maturation, which is considered to be equal to the physiological stress response experienced by pre-term infants. Experimental and simulation studies concluded that this is met by a daily intake of $0.288 \mathrm{mg} / \mathrm{kg}$ of dexamethasone sodium phosphate $(12 \mu \mathrm{g} / \mathrm{kg} / \mathrm{h}$ by infusion i.m.) on GDs 18-21, achieving steady-state free plasma concentrations of $9 \mathrm{nM}$, roughly twice the $K_{\mathrm{dDEx}}$ of $4.7 \mathrm{nM}$. This is approximately four-fold the prenatal dose given by the oral route in our study. Therefore, by extrapolation, it is likely that the prenatal dosing regimen in this study will have achieved only a fraction of these plasma concentrations which appear not to fully suppress the endogenous HPA axis (Samtani et al, 2006b). Although similar experimental data are not available for neonatal treatments, theoretical and empirical evidence support the view that the dose of dexamethasone used in the present study is modest. The amount of dexamethasone that actually reaches the developing brain is also a complex issue. The multi-drug resistance gene product, P-glycoprotein, that extrudes all but $5-10 \%$ of circulating dexamethasone from the adult brain has not been detected in the rat before P7 (Matsuoka et al, 1999). Additionally, GRs are expressed in the basal ganglia from E15.5 in the rat (Diaz et al, 1998). It is therefore feasible that dexamethasone may exert its actions directly in the developing brain.

If the maternal dose of dexamethasone is sufficiently great, there is a possibility that effects on the offspring may be secondary to a detrimental effect on maternal care which, in turn, is known to have enduring effects on behavior and neuroendocrine function (Szyf et al, 2005). This notion is supported by a cross-fostering study where adult offspring exposed to dexamethasone via the maternal drinking water from E15 until parturition were more affected in certain measures of learning, HPA function, and body weight if reared by mothers treated prenatally with dexamethasone compared with dams receiving normal drinking water (Brabham et al, 2000). However, the concentration of dexamethasone $(2.5 \mu \mathrm{g} / \mathrm{ml})$ was five times that used in our prenatal treatment regimen, and caused restlessness in the mothers during the first week postpartum as well as increased neonatal mortality. Although we have not performed a detailed analysis of maternal behavior in the present study, the pups thrived and observation by staff experienced in animal husbandry detected no deleterious effects on behavior. Moreover, another study using double our prenatal concentration of dexamethasone in the drinking water made a detailed analysis of maternal behavior in the first week after birth and reported a positive rather than negative effect (Hauser et al, 2006). It would also appear that cross-fostering per se may not be without significant effects on maternal behaviors (Maccari et al, 1995) and has been reported to reduce baseline and nicotine-stimulated DA secretion in the nucleus accumbens (Kane et al, 2004). On the other hand, certain programming effects of prenatal dexamethasone treatment were unaffected by cross-fostering to control dams, suggesting that the GC effects operate directly in the fetus (Nyirenda et al, 2001). On balance, the foregoing considerations illustrate the value of selecting a minimally intrusive treatment protocol, along with exposure to modest doses of dexamethasone, as a valid approach to investigating neurobiological programming by GCs.

\section{Midbrain DA Population Size}

Inherent sex differences. There is not a consensus in the literature on the total number of DA neurons in the midbrain nuclei. In the adult rat SNc estimates of TH-IR cell numbers include 3500 (Anden et al, 1966), 7300 (Hedreen and Chalmers, 1972), and 10500 (German and Manaye, 1993). Where sex has been taken into consideration, the adult male rat $\mathrm{SNc}$ contains significantly more DA neurons (approximately 11500) than the female nucleus (approximately 9000) (Dewing et al, 2006). Our values of $7396 \pm 184$ (males) and $6637 \pm 243$ (females) closely approximate the average of the published estimates and confirm a maledominant sex difference. There are fewer publications on VTA cell numbers, and, although our data for males (5167 $+118)$ and females $(6202+121)$ fall below other estimates in rats of 10,200 (German and Manaye, 1993) and 18723 (Ling et al, 2004), they are of a similar magnitude to those for the SNc, which is in agreement with other studies in the rat (German and Manaye, 1993) and the mouse (Blum, 1998). In addition, we believe that our data are the first to show that there is a significant sex difference in DA neuron numbers in the VTA but, unlike the SNc, values are greater in females than males. As well as methodological differences, the strain of animal is likely to be a source of difference in values quoted for total TH-IR cell counts, which can vary as much as three-fold in mice (Blum, 1998). However, the main aim of the present study was to investigate differences between treatments rather than absolute values, and measures to ensure this included processing of tissue in batches selected across treatment groups and data collection by an investigator blind to treatment groups as well as strict adherence to identical protocols for all batches.

Numerous investigations suggest that sex steroid hormones, acting either during development or in adulthood, are major determinants of sex differences in the number of 
total neurons or specific neurotransmitter populations in certain brain nuclei (Forger, 2006). However, it was recently demonstrated that specific expression of the Sry gene in DA neurons of the SNc is responsible for the larger population of TH-IR cells in the male nucleus (Dewing et al, 2006). Additionally, our own studies (McArthur et al, 2006b) failed to demonstrate a role for SSHs in maintaining the maledominant sex difference in numbers of DA neurons in the adult SNc. Factors responsible for the female-dominant sex differences in the VTA remain to be determined.

Influence of perinatal GC exposure. In both sexes a similar, robust increase of 65 and $50 \%$ in the total DA cell counts was seen in the adult VTA after pre- and neonatal GC treatment, respectively, which was due to significant effects at all levels through the region. Although more moderate, a significant increase in total TH-IR cell count was also seen in the SNc after prenatal and neonatal treatments in adult females (31 and 35\%, respectively) and males (24 and $22 \%$, respectively). Like the VTA, this effect was present throughout the female SNc (A-D), but in the male SNc effects were restricted to only two levels after both prenatal (B and D) and neonatal (A and D) treatments. These data largely agree with our initial findings at level B (average TH-IR cell counts per section), except the present analyses throughout the nuclei also reveal a significant overall effect of neonatal GC treatment in the male SNc. Together, the results demonstrate that the developing VTA is exquisitely sensitive to relatively mild, transient increments in circulating GCs in both sexes. Along with the more muted responses in the male and female SNc and the lack of a consistent effect in the male SNc, these findings illustrate that the enduring effects of inappropriate perinatal exposure to GCs are both population specific and sexually dimorphic. This is further supported by our studies on hypothalamic DA neurons where perinatal GC treatment fails to affect populations in the periventricular nucleus, but reduces the population size in the arcuate nucleus (McArthur et al, 2006 b) only in females, not in males.

It is known that physiological levels of GCs augment DA activity in the striatum (Piazza et al, 1996a) and evidence suggests that perinatal exposure to synthetic GCs alters the responsiveness of the adult HPA axis (Weinstock, 2001; Welberg et al, 2001; Owen et al, 2005). It should therefore be considered whether the effects of perinatal GC exposure could be secondary to changes in the prevailing adult levels of the adrenal steroid. Importantly, however, maternal GC treatment appears to have opposite effects on basal and stimulated GC levels in adult males and females, and qualitative differences have been reported for HPA axis activity after pre- and neonatal GC exposure (Weinstock, 2001; Kamphuis et al, 2003; Owen et al, 2005). Thus it is unlikely that these contrasting effects on the HPA axis can be causative for the qualitatively similar effects of both our treatment regimens on the adult midbrain DA populations. Moreover, evidence suggests that although $\mathrm{TH}$ activity may be influenced by GCs, TH-IR cell counts in the SNc and VTA are not affected by adult adrenalectomy or GC treatment (Piazza et al, 1996b; Mizoguchi et al, 2004). The balance of evidence would thus favor a primary effect of dexamethasone on the developing neurons. In support of this, it has been demonstrated that synthetic GCs do reach the developing brain (Meaney et al, 1985; Owen et al, 2005) and expression of GRs is detectable in the basal ganglia from E15.5 in the rat (Chatelain et al, 1980), but their colocalization with DA in the developing SNc has not been determined.

Although the mechanisms for determining the adult cell number in the mesencephalic DA system are not fully understood, a number of critical developmental processes could be targeted by our GC treatment regimens. In the rat the final mitosis of DA progenitor cells occurs between E12 and E16 (Bayer et al, 1995; Lieb et al, 1996), which just overlaps with our pretreatment regimen beginning at E16. However, if findings based on proliferation rate of the granule cells in the hippocampal dentate gyrus are more generally applicable (Gould and Cameron, 1996), it would be predicted that adrenal steroids might decrease neurogenesis, which would not be compatible with our reported increase in midbrain DA cell numbers. The main migratory period for TH-expressing cells into the SN and VTA is also complete around E16 (Kawano et al, 1995), so interference with the arrival of DA neurons into these regions would also have limited or no potential to explain the enduring effects of preand neonatal GC treatments, respectively. Notably, however, in the mouse, which exhibits an identical pattern of midbrain DA neuron development to the rat, the sharpest rise in mesencephalic TH-IR cell numbers occurs during late gestation (E17-21) (Lieb et al, 1996) and the proportion of total neurons that are $\mathrm{TH}$ positive in the SNc continues to rise postnatally to reach adult levels by P7-9 (Kholodilov et al, 2004), P14 (Jackson-Lewis et al, 2000), or P28 (Lieb et $a l, 1996)$. At this stage upregulation of $\mathrm{TH}$ expression has been proposed as a major factor in determining DA neuron numbers (Lieb et al, 1996). As the TH gene contains a GC response element (Hagerty et al, 2001), it is possible that GCs could directly influence terminal differentiation to the DA phenotype during pre- and neonatal development. Equally, GCs could influence the cascade of other factors, such as Nurr-1, that are known to induce and/or maintain the midbrain DA phenotype (Vitalis et al, 2005). Naturally occurring cell death via apoptotic mechanisms is also a process thought to play a critical role during late gestation and the neonatal period in regulating adult numbers of DA neurons in the SN (Jackson-Lewis et al, 2000; Oo et al, 2003; Burke, 2004; Kholodilov et al, 2004; Vitalis et al, 2005). Although GCs are often thought of as inducers of apoptosis (Schmidt et al, 2004), they can also suppress apoptosis and promote survival in certain cell types (Abraham et al, 2001; Amsterdam et al, 2002). Specifically, in the brain endogenous adrenal steroids have been shown to promote the survival of hippocampal granule cells of the dentate gyrus, and it has been proposed that the period of hyporesponsiveness in the HPA axis just after birth, that lowers the prevailing hormone levels, enables natural cell death to occur (Gould and Cameron, 1996; Abraham et al, 2001). Future studies will reveal whether our perinatal GC treatment regimens similarly oppose this period of cell death in midbrain DA neurons to affect DA cell counts in the adult SN or VTA.

\section{GC Programming of Midbrain DA Cytoarchitecture}

Inherent sex difference. Here we show for the first time that the total volumes occupied by the TH-IR cells of the SNc 
and VTA are greater in females compared with males. Our results show that this is not due to a sex difference in TH-IR cell size, nor can it be due to additional neurons of the DA phenotype, which are less abundant in the female $S N$, but more abundant in the female VTA. Future studies will be required to determine the contribution of other cell types, such as glia, to these differences.

Whatever the underlying cause, our results at the regional level reveal, also, a remarkable sex difference in the control animals in both the overall shape of the nuclei, as shown by the pattern of the volumes at each level, and in the distribution of DA cells across the levels. In the SNc this is characterized in males by the presence of the largest volume and percentage of cells at level A, which both exceed by twoto three-fold the values at each of levels $B, C$, and D. In contrast, in the female SNc the volume at level C is doubled, and at D is substantially increased compared with males, and greater percentages of cells are also found at C and D. In the VTA level $\mathrm{C}$ also stands out as possessing distinguishing features between the sexes because the greatest volume and $50 \%$ of the DA cells are concentrated at this level in females, whereas a more equal distribution is seen in males. In general terms, these findings thus show that both the volume and distribution of cells are shifted from the rostral to caudal direction in females relative to males. Although evidence for sex differences in the total volume of various nuclei in the CNS is relatively well documented (Forger, 2006), we believe that this is the first demonstration of a sex difference in the 3D cytoarchitecture of the midbrain DA systems. It remains to be determined whether sex steroid hormones play an important role in determining these differences, as they do in other nuclei (Simerly, 2005; Forger, 2006). However, there are clear sex differences in the behavioral, neurochemical, and neurodegenerative responses within the NSDA pathway (Becker, 1999; Murray et al, 2003; Gillies et al, 2004) which, we propose, may arise, to a large extent, from the sexually differentiated cytoarchitecture. Evidence for sex differences in the mesocorticolimbic pathways is less clear, but may be inferred from sex differences in the prevalence or severity of psychiatric disorders, such as anxiety and depression, with which their malfunction is associated (Shansky et al, 2004).

Influence of perinatal GCs. Our results show that perinatal GC exposure dramatically changes the shape of the midbrain DA nuclei as well as the distribution of the DA neurons within them. This can generally be described as an expansion and/or shifting of the regional volume and distribution of cells in a caudal direction to levels $C$ and D in males, and level $\mathrm{D}$ in females (where these parameters are already shifted relative to males). For example, in the male $\mathrm{SNc}$ and VTA prenatal GC treatment markedly increased regional volumes and the percentages of DA neurons located at both $\mathrm{C}$ and $\mathrm{D}$ such that the overall shape and neuronal distribution were remarkably similar to that seen in females. A largely similar effect was seen with neonatal GC treatment in males, but effects are more prevalent at $\mathrm{C}$ rather than $\mathrm{D}$, especially for VTA regional volumes and for distribution of DA neurons in the SNc. In contrast to males, in the female SNc and VTA prenatal GC treatment actually decreased regional volumes and percentage of DA neurons at $C$, but increased them at D. Neonatal treatment had a broadly similar effect. Together, these data suggest that perinatal GC treatment interferes with the sexual differentiation of the SNc and VTA cytoarchitecture and, in particular, results in a feminization or demasculinization in the male. Notably, prenatal exposure to dexamethasone or stress (which would increase endogenous adrenal steroids) have been reported to demasculinize or feminize reproductive behaviors in adult male rats (Ward, 1972; Holson et al, 1995). Recent studies have also shown that prenatal dexamethasone treatment eliminated sex differences in locomotor and cognitive behaviors by distinct and often opposite effects in males and females (Kreider et al, 2005). In addition, both pre- and neonatal dexamethasone treatments altered indicies of cell number and size (DNA and protein levels) and synaptic activity in forebrain regions in a sex-and time-dependent manner (Kreider et al, 2006). Our results therefore add new evidence to support the concept that perinatal GC exposure disrupts the normal sexual differentiation of the brain. Although the differences between pre- and neonatal dexamethasone treatments in the present study are relatively subtle, they also support the view that the consequences of GC actions in the developing brain are critically dependent on the window of exposure.

Functional and clinical implications of perinatal GC programming of midbrain DA systems. Although the midbrain DA populations are conveniently compartmentalised anatomically as the VTA and $\mathrm{SNc}$, functionally they comprise subsets of neurons with different input and output systems. For example, DA innervation of the PFC in the rat originates from neurons distributed in the anterior-middle part of the VTA and these are dissociated from others located in the VTA that project to subcortical structures, such as the nucleus accumbens (Tassin et al, 1982). Equally, neurons originating from the dorsal raphe, and projecting to the VTA, regulate activity of the meso-nucleus accumbens DA neurons, but not that of the mesocortical DA neurons, indicating a region-specific organization of afferent pathways (Herve et al, 1979). It is therefore highly likely that the changes in topographical organization and numbers of adult midDA neurons consequent on exposure to raised levels of GCs in early life will have a significant impact on functionality in these systems. In support of this, a recent study in transgenic mice described an increase in the size of the SNc DA population, as well as expansion of its volume caudally, resulting from a caudal shift in the midbrain-hindbrain organizer, and this was accompanied by enhanced locomotor activity (Brodski et al, 2003). Further evidence for functional changes is provided by the observation that prenatal and neonatal dexamethasone treatments increase DA levels in the adult cerebral cortex regions receiving an input from the VTA (Slotkin et al, 2006).

Synthetic GCs such as dexamethasone are widely used in cases of threatened pre-term birth because they promote fetal lung development and reduce mortality rate in premature infants (Liggins and Howie, 1972). These benefits are undisputed, but there is growing concern over the use of repeated courses of GCs prenatally and their increasing use postnatally where the clinical benefits are poorly established (Finer et al, 2000; Yeh et al, 2004). The present data 
therefore provide substantial new evidence that exposure to synthetic GCs $(0.075-0.15 \mathrm{mg} / \mathrm{kg} /$ day $)$ at doses in the lower range or below those used in perinatal medicine (Jobe and Soll, 2004; Yeh et al, 2004; Kreider et al, 2006) can permanently disrupt the structural development and population size in DA pathways that are critical for normal behavioral, emotional, and cognitive processes. Although dexamethasone clearly lacks the mineralocorticoid receptor activity of cortisol/corticosterone released endogenously, the present findings raise the possibility that stress-induced elevations in maternal GCs (which are reflected in the fetal circulation (Gitau et al, 1998)) or activation of the fetal HPA axis (Gitau et al, 2001), could equally target the developing midbrain systems and contribute to behavioral disturbances and possibly the emergence of certain psychiatric conditions associated with disruption in these pathways, such as schizophrenia or ADHD.

In conclusion, this study has demonstrated that perinatal exposure to relatively low doses of the synthetic GC, dexamethasone, increases the size and alters the distribution of the adult DA populations in the SNc and VTA. In addition, the findings provide evidence of a sexual dimorphism in the topographical arrangement of the DA neurons within these regions that provide a structural basis for the known sexually dimorphic properties of the nigrostriatal DA pathway, and would predict similar functional dimorphisms for the mesolimbic and mesocortical pathways. Future studies will be carried out to determine precisely the impact of these cytoarchitectural changes on local circuitry and functional integration.

\section{ACKNOWLEDGEMENTS}

We thank Mr Colin Rantle and Ms Devinder Mehet for expert technical assistance. We are grateful to The Wellcome Trust and Hammersmith Hospitals Research Trust Committee for financial support.

\section{REFERENCES}

Abraham IM, Harkany T, Horvath KM, Luiten PG (2001). Action of glucocorticoids on survival of nerve cells: promoting neurodegeneration or neuroprotection? J Neuroendocrinol 13: 749-760.

Amsterdam A, Tajima K, Sasson R (2002). Cell-specific regulation of apoptosis by glucocorticoids: implication to their anti-inflammatory action. Biochem Pharmacol 64: 843-850.

Anden NE, Hfuxe K, Hamberger B, Hokfelt T (1966). A quantitative study on the nigro-neostriatal dopamine neuron system in the rat. Acta Physiol Scand 67: 306-312.

Barbazanges A, Piazza PV, Le Moal M, Maccari S (1996). Maternal glucocorticoid secretion mediates long-term effects of prenatal stress. J Neurosci 16: 3943-3949.

Barker DJ (1995). The Wellcome Foundation Lecture, 1994. The fetal origins of adult disease. Proc Biol Sci 262: 37-43.

Bayer SA, Wills KV, Triarhou LC, Ghetti B (1995). Time of neuron origin and gradients of neurogenesis in midbrain dopaminergic neurons in the mouse. Exp Brain Res 105: 191-199.

Becker JB (1999). Gender differences in dopaminergic function in striatum and nucleus accumbens. Pharmacol Biochem Behav 64: 803-812.

Benes FM, Lange N (2001). Two-dimensional versus three-dimensional cell counting: a practical perspective. Trends Neurosci 24: 11-17.
Blum M (1998). A null mutation in TGF-alpha leads to a reduction in midbrain dopaminergic neurons in the substantia nigra. Nat Neurosci 1: 374-377.

Bonthius DJ, McKim R, Koele L, Harb H, Karacay B, Mahoney J et al (2004). Use of frozen sections to determine neuronal number in the murine hippocampus and neocortex using the optical disector and optical fractionator. Brain Res Brain Res Protoc 14: 45-57.

Braak H, Ghebremedhin E, Rub U, Bratzke H, Del Tredici K (2004). Stages in the development of Parkinson's disease-related pathology. Cell Tissue Res 318: 121-134.

Brabham T, Phelka A, Zimmer C, Nash A, Lopez JF, Vazquez DM (2000). Effects of prenatal dexamethasone on spatial learning and response to stress is influenced by maternal factors. Am J Physiol Regul Integr Comp Physiol 279: R1899-1909.

Brake WG, Flores G, Francis D, Meaney MJ, Srivastava LK, Gratton A (2000b). Enhanced nucleus accumbens dopamine and plasma corticosterone stress responses in adult rats with neonatal excitotoxic lesions to the medial prefrontal cortex. Neuroscience 96: 687-695.

Brake WG, Sullivan RM, Gratton A (2000a). Perinatal distress leads to lateralized medial prefrontal cortical dopamine hypofunction in adult rats. J Neurosci 20: 5538-5543.

Brodski C, Weisenhorn DM, Signore M, Sillaber I, Oesterheld M, Broccoli $\mathrm{V}$ et al (2003). Location and size of dopaminergic and serotonergic cell populations are controlled by the position of the midbrain-hindbrain organizer. $J$ Neurosci 23: 4199-4207.

Burke RE (2004). Ontogenic cell death in the nigrostriatal system. Cell Tissue Res 318: 63-72.

Carman LS, Gage FH, Shults CW (1991). Partial lesion of the substantia nigra: relation between extent of lesion and rotational behavior. Brain Res 553: 275-283.

Chatelain A, Dupouy JP, Allaume P (1980). Fetal-maternal adrenocorticotropin and corticosterone relationships in the rat: effects of maternal adrenalectomy. Endocrinology 106: 1297-1303.

Cotter D, Pariante CM (2002). Stress and the progression of the developmental hypothesis of schizophrenia. Br J Psychiatry 181: 363-365.

Datla KP, Murray HE, Pillai AV, Gillies GE, Dexter DT (2003). Differences in dopaminergic neuroprotective effects of estrogen during estrous cycle. Neuroreport 14: 47-50.

Dewing P, Chiang CW, Sinchak K, Sim H, Fernagut PO, Kelly S et al (2006). Direct regulation of adult brain function by the male-specific factor SRY. Curr Biol 16: 415-420.

Dexter DT, Nanayakkara I, Goss-Sampson MA, Muller DP, Harding AE, Marsden CD et al (1994). Nigral dopaminergic cell loss in vitamin E deficient rats. Neuroreport 5: 1773-1776.

Diaz R, Brown RW, Seckl JR (1998). Distinct ontogeny of glucocorticoid and mineralocorticoid receptor and 11beta-hydroxysteroid dehydrogenase types I and II mRNAs in the fetal rat brain suggest a complex control of glucocorticoid actions. J Neurosci 18: 2570-2580.

Finer NN, Craft A, Vaucher YE, Clark RH, Sola A (2000). Postnatal steroids: short-term gain, long-term pain? J Pediatr 137: 9-13.

Forger NG (2006). Cell death and sexual differentiation of the nervous system. Neuroscience 138: 929-938.

Funkhouser JD, Peevy KJ, Mockridge PB, Hughes ER (1978). Distribution of dexamethasone between mother and fetus after maternal administration. Pediatr Res 12: 1053-1056.

German DC, Manaye KF (1993). Midbrain dopaminergic neurons (nuclei A8, A9, and A10): three-dimensional reconstruction in the rat. J Comp Neurol 331: 297-309.

Gillies GE, Murray HE, Dexter D, McArthur S (2004). Sex dimorphisms in the neuroprotective effects of estrogen in an animal model of Parkinson's disease. Pharmacol Biochem Behav 78: $513-522$. 
Gitau R, Cameron A, Fisk NM, Glover V (1998). Fetal exposure to maternal cortisol. Lancet 352: 707-708.

Gitau R, Fisk NM, Teixeira JM, Cameron A, Glover V (2001). Fetal hypothalamic-pituitary-adrenal stress responses to invasive procedures are independent of maternal responses. J Clin Endocrinol Metab 86: 104-109.

Gould E, Cameron HA (1996). Regulation of neuronal birth, migration and death in the rat dentate gyrus. Dev Neurosci 18: 22-35.

Hagerty T, Morgan WW, Elango N, Strong R (2001). Identification of a glucocorticoid-responsive element in the promoter region of the mouse tyrosine hydroxylase gene. J Neurochem 76: 825-834.

Hart AM, Terenghi G (2004). Frozen-section fluorescence microscopy and stereology in the quantification of neuronal death within dorsal root ganglia. J Mol Histol 35: 565-580.

Hauser J, Feldon J, Pryce CR (2006). Prenatal dexamethasone exposure, postnatal development, and adulthood prepulse inhibition and latent inhibition in Wistar rats. Behav Brain Res 175: 51-61.

Hedreen JC, Chalmers JP (1972). Neuronal degeneration in rat brain induced by 6-hydroxydopamine; a histological and biochemical study. Brain Res 47: 1-36.

Henry C, Guegant G, Cador M, Arnauld E, Arsaut J, Le Moal M et al (1995). Prenatal stress in rats facilitates amphetamineinduced sensitization and induces long-lasting changes in dopamine receptors in the nucleus accumbens. Brain Res 685: 179-186.

Herve D, Simon H, Blanc G, Lisoprawski A, Le Moal M, Glowinski J et al (1979). Increased utilization of dopamine in the nucleus accumbens but not in the cerebral cortex after dorsal raphe lesion in the rat. Neurosci Lett 15: 127-133.

Holson RR, Gough B, Sullivan P, Badger T, Sheehan DM (1995). Prenatal dexamethasone or stress but not ACTH or corticosterone alter sexual behavior in male rats. Neurotoxicol Teratol 17: 393-401.

Hynes M, Rosenthal A (1999). Specification of dopaminergic and serotonergic neurons in the vertebrate CNS. Curr Opin Neurobiol 9: $26-36$.

Jackson-Lewis V, Vila M, Djaldetti R, Guegan C, Liberatore G, Liu J et al (2000). Developmental cell death in dopaminergic neurons of the substantia nigra of mice. J Comp Neurol 424: $476-488$.

Jobe AH, Soll RF (2004). Choice and dose of corticosteroid for antenatal treatments. Am J Obstet Gynecol 190: 878-881.

Kamphuis PJ, Gardoni F, Kamal A, Croiset G, Bakker JM, Cattabeni $\mathrm{F}$ et al (2003). Long-lasting effects of neonatal dexamethasone treatment on spatial learning and hippocampal synaptic plasticity: involvement of the NMDA receptor complex. FASEB $J$ 17: 911-913.

Kane VB, Fu Y, Matta SG, Sharp BM (2004). Gestational nicotine exposure attenuates nicotine-stimulated dopamine release in the nucleus accumbens shell of adolescent Lewis rats. J Pharmacol Exp Ther 308: 521-528.

Kawano H, Ohyama K, Kawamura K, Nagatsu I (1995). Migration of dopaminergic neurons in the embryonic mesencephalon of mice. Brain Res Dev Brain Res 86: 101-113.

Kholodilov N, Yarygina O, Oo TF, Zhang H, Sulzer D, Dauer W et al (2004). Regulation of the development of mesencephalic dopaminergic systems by the selective expression of glial cell line-derived neurotrophic factor in their targets. J Neurosci 24: 3136-3146.

Kreider ML, Levin ED, Seidler FJ, Slotkin TA (2005). Gestational dexamethasone treatment elicits sex-dependent alterations in locomotor activity, reward-based memory and hippocampal cholinergic function in adolescent and adult rats. Neuropsychopharmacology 30: 1617-1623.

Kreider ML, Tate CA, Cousins MM, Oliver CA, Seidler FJ, Slotkin TA (2006). Lasting effects of developmental dexamethasone treatment on neural cell number and size, synaptic activity, and cell signaling: critical periods of vulnerability, dose-effect relationships, regional targets, and sex selectivity. Neuropsychopharmacology 31: 12-35.

Lewis DA, Levitt P (2002). Schizophrenia as a disorder of neurodevelopment. Annu Rev Neurosci 25: 409-432.

Lieb K, Andersen C, Lazarov N, Zienecker R, Urban I, Reisert I et al (1996). Pre- and postnatal development of dopaminergic neuron numbers in the male and female mouse midbrain. Brain Res Dev Brain Res 94: 37-43.

Liggins GC, Howie RN (1972). A controlled trial of antepartum glucocorticoid treatment for prevention of the respiratory distress syndrome in premature infants. Pediatrics 50: 515-525.

Ling ZD, Chang Q, Lipton JW, Tong CW, Landers TM, Carvey PM (2004). Combined toxicity of prenatal bacterial endotoxin exposure and postnatal 6-hydroxydopamine in the adult rat midbrain. Neuroscience 124: 619-628.

Maccari S, Piazza PV, Kabbaj M, Barbazanges A, Simon H, Le Moal $M$ (1995). Adoption reverses the long-term impairment in glucocorticoid feedback induced by prenatal stress. J Neurosci 15: $110-116$.

Matsuoka Y, Okazaki M, Kitamura Y, Taniguchi T (1999). Developmental expression of P-glycoprotein (multidrug resistance gene product) in the rat brain. J Neurobiol 39: 383-392.

McArthur S, McHale E, Dalley JW, Buckingham JC, Gillies GE (2005). Altered mesencephalic dopaminergic populations in adulthood as a consequence of brief perinatal glucocorticoid exposure. J Neuroendocrinol 17: 475-482.

McArthur S, Siddique ZL, Christian HC, Capone G, Theogaraj E, John CD et al (2006a). Perinatal glucocorticoid treatment disrupts the hypothalamo-lactotroph axis in adult female, but not male, rats. Endocrinology 147: 1904-1915.

McArthur S, Murray HE, Dhankot A, Dexter DT, Gillies GE (2006b). Striatal susceptibility to a dopaminergic neurotoxin is independent of sex hormone effects on cell survival and DAT expression but is exacerbated by central aromatase inhibition. $J$ Neurochem [Epub ahead of print].

Meaney MJ, Brake W, Gratton A (2002). Environmental regulation of the development of mesolimbic dopamine systems: a neurobiological mechanism for vulnerability to drug abuse? Psychoneuroendocrinology 27: 127-138.

Meaney MJ, Sapolsky RM, Aitken DH, McEwen BS (1985). $[3 \mathrm{H}]$ dexamethasone binding in the limbic brain of the fetal rat. Brain Res 355: 297-300.

Melichar JK, Daglish MR, Nutt DJ (2001). Addiction and withdrawal-current views. Curr Opin Pharmacol 1: 84-90.

Mizoguchi K, Ishige A, Takeda S, Aburada M, Tabira T (2004). Endogenous glucocorticoids are essential for maintaining prefrontal cortical cognitive function. J Neurosci 24: 5492-5499.

Moore RY, Bloom FE (1978). Central catecholamine neuron systems: anatomy and physiology of the dopamine systems. Annu Rev Neurosci 1: 129-169.

Morris JA, Jordan CL, Dugger BN, Breedlove SM (2005). Partial demasculinization of several brain regions in adult male (XY) rats with a dysfunctional androgen receptor gene. J Comp Neurol 487: 217-226.

Mullen RJ, Buck CR, Smith AM (1992). NeuN, a neuronal specific nuclear protein in vertebrates. Development 116: 201-211.

Murray HE, Pillai AV, McArthur SR, Razvi N, Datla KP, Dexter DT et al (2003). Dose- and sex-dependent effects of the neurotoxin 6-hydroxydopamine on the nigrostriatal dopaminergic pathway of adult rats: differential actions of estrogen in males and females. Neuroscience 116: 213-222.

Nyirenda MJ, Welberg LA, Seckl JR (2001). Programming hyperglycaemia in the rat through prenatal exposure to glucocorticoids-fetal effect or maternal influence? J Endocrinol 170: 653-660. 
Oo TF, Burke RE (1997). The time course of developmental cell death in phenotypically defined dopaminergic neurons of the substantia nigra. Brain Res Dev Brain Res 98: 191-196.

Oo TF, Kholodilov N, Burke RE (2003). Regulation of natural cell death in dopaminergic neurons of the substantia nigra by striatal glial cell line-derived neurotrophic factor in vivo. J Neurosci 23: 5141-5148.

Owen D, Andrews MH, Matthews SG (2005). Maternal adversity, glucocorticoids and programming of neuroendocrine function and behaviour. Neurosci Biobehav Rev 29: 209-226.

Paxinos G, Watson C (1986). The Rat Brain in Stereotaxic Coordinates. Academic press: San Diego, CA.

Piazza PV, Barrot M, Rouge-Pont F, Marinelli M, Maccari S, Abrous DN et al (1996b). Suppression of glucocorticoid secretion and antipsychotic drugs have similar effects on the mesolimbic dopaminergic transmission. Proc Natl Acad Sci USA 93: $15445-15450$.

Piazza PV, Rouge-Pont F, Deroche V, Maccari S, Simon H, Le Moal M (1996a). Glucocorticoids have state-dependent stimulant effects on the mesencephalic dopaminergic transmission. Proc Natl Acad Sci USA 93: 8716-8720.

Samtani MN, Pyszczynski NA, Dubois DC, Almon RR, Jusko WJ (2006a). Modeling glucocorticoid-mediated fetal lung maturation: I. Temporal patterns of corticosteroids in rat pregnancy. J Pharmacol Exp Ther 317: 117-126.

Samtani MN, Pyszczynski NA, Dubois DC, Almon RR, Jusko WJ (2006b). Modeling glucocorticoid-mediated fetal lung maturation: II. Temporal patterns of gene expression in fetal rat lung. J Pharmacol Exp Ther 317: 127-138.

Schmidt S, Rainer J, Ploner C, Presul E, Riml S, Kofler R (2004). Glucocorticoid-induced apoptosis and glucocorticoid resistance: molecular mechanisms and clinical relevance. Cell Death Differ 11(Suppl 1): S45-S55.

Shansky RM, Glavis-Bloom C, Lerman D, McRae P, Benson C, Miller $\mathrm{K}$ et al (2004). Estrogen mediates sex differences in stress-induced prefrontal cortex dysfunction. Mol Psychiatry 9: 531-538.

Simerly RB (2005). Wired on hormones: endocrine regulation of hypothalamic development. Curr Opin Neurobiol 15: 81-85.

Slotkin TA, Kreider ML, Tate CA, Seidler FJ (2006). Critical prenatal and postnatal periods for persistent effects of dexamethasone on serotonergic and dopaminergic systems. Neuropsychopharmacology 31: 904-911.

Solanto MV (2002). Dopamine dysfunction in AD/HD: integrating clinical and basic neuroscience research. Behav Brain Res 130: $65-71$.
Szyf M, Weaver IC, Champagne FA, Diorio J, Meaney MJ (2005). Maternal programming of steroid receptor expression and phenotype through DNA methylation in the rat. Front Neuroendocrinol 26: 139-162.

Tainturier D, Alvinerie M, Brandon RA, Toutain PL (1982). Dexamethasone concentrations in bovine blood plasma and milk after intravenous injection. J Dairy Sci 65: 1921-1924.

Tassin JP, Simon H, Herve D, Blanc G, Le Moal M, Glowinski J et al (1982). Non-dopaminergic fibres may regulate dopaminesensitive adenylate cyclase in the prefrontal cortex and nucleus accumbens. Nature 295: 696-698.

Tepper JM, Damlama M, Trent F (1994). Postnatal changes in the distribution and morphology of rat substantia nigra dopaminergic neurons. Neuroscience 60: 469-477.

Theogaraj E, John CD, Christian HC, Morris JF, Smith SF, Buckingham JC (2005). Perinatal glucocorticoid treatment produces molecular, functional, and morphological changes in the anterior pituitary gland of the adult male rat. Endocrinology 146: 4804-4813.

Theogaraj E, John CD, Dewar A, Buckingham JC, Smith SF (2006). The long-term effects of perinatal glucocorticoid exposure on the host defence system of the respiratory tract. J Pathol 210: 85-93.

Van den Bergh BR, Mulder EJ, Mennes M, Glover V (2005). Antenatal maternal anxiety and stress and the neurobehavioural development of the fetus and child: links and possible mechanisms. Rev Neurosci Biobehav Rev 29: 237-258.

Vitalis T, Cases O, Parnavelas JG (2005). Development of the dopaminergic neurons in the rodent brainstem. Exp Neurol 191(Suppl 1): S104-S112.

Ward IL (1972). Prenatal stress feminizes and demasculinizes the behavior of males. Science 175: 82-84.

Weinstock M (2001). Alterations induced by gestational stress in brain morphology and behaviour of the offspring. Prog Neurobiol 65: 427-451.

Welberg LA, Seckl JR (2001). Prenatal stress, glucocorticoids and the programming of the brain. J Neuroendocrinol 13: 113-128.

Welberg LA, Seckl JR, Holmes MC (2001). Prenatal glucocorticoid programming of brain corticosteroid receptors and corticotrophin-releasing hormone: possible implications for behaviour. Neuroscience 104: 71-79.

Yeh TF, Lin YJ, Lin HC, Huang CC, Hsieh WS, Lin $\mathrm{CH}$ et al (2004). Outcomes at school age after postnatal dexamethasone therapy for lung disease of prematurity. $N$ Engl J Med 350: 1304-1313. 